\title{
The Benefits of HIV/AIDS Intervention in the Workplace: A Case Study ${ }^{1}$
}

F le R Booysen

Department of Economics, University of the Free State

J Molelekoa

Department of Economics, Vista University Welkom

\section{ABSTRACT}

Over the next ten years, as the AIDS epidemic takes its toll on the economically active population, employers will incur considerable costs. However, relatively inexpensive interventions, if implemented now, can yield substantial returns and save business considerable amounts of money. Thus, social responsibility can be argued to make economic sense. Worrying, though, is that there also appears to be a general apathy on the part of business, especially amongst small and medium-sized enterprises. A lot needs to be done to change the attitude of business and get business actively involved in the fight against HIV/AIDS. The private sector can and need to do its share in an integrated, coordinated response to HIV/AIDS, thus contributing to the initiatives on which the government, NGOs and communities have already embarked.

JEL J50

The HIV/AIDS epidemic poses a great threat to the economies of developing countries and those on the African continent in particular. South Africa is no exception and is being affected fundamentally by the epidemic. By the end of 1997, some 2.8 million people were estimated to be living with HIV/AIDS in South Africa (ILO, 2000: 7). The estimated prevalence of HIV/AIDS among the country's adult population (11.8 per cent) is amongst the highest in the world. South Africa also has the largest number of people living with HIV/AIDS of all countries (UNAIDS, 2000). According to the MetropolitanDoyle model, the number of South African living with HIV/AIDS will increase from 160000 to almost one million between 2000 and 2010. The annual number of AIDS deaths is estimated to increase from 120000 to between 545 and 635 thousand between 2000 and 2010 (Abt Associates, 2000: 8-9). 
The epidemic has the potential to completely erode economic gains made in past decades. As the disease takes its toll on the economically active population, production and demand are expected to decline, which will slow down economic growth and development. Studies on the macroeconomic impact of the disease have estimated that the differential in the economic growth rate will be 2010 amount to between 0.4 and 2.6 percentage points (Arndt \& Lewis, 2000; ING Barings, 2000: 2). The epidemic will also have serious budgetary implications in terms of increased government expenditure on health care and social security, which will be aggravated by the decline in government revenue due to declining economic activity (Barnett \& Whiteside, 1998; ILO, 2000).

Employers will also incur considerable costs as the disease takes its toll on the economically active population. These costs result from increased absenteeism, direct and indirect medical costs, increased labor tumover, decreased productivity, and employee benefits payable to employees living with and dying from HIV/AIDS (Bollinger \& Stover, 1999; Whiteside \& Sunter, 2000: 11012). The degree of impact depends on (i) how many people are infected, (ii) the role of the infected persons in the company, (iii) the nature of the production process, (iv) the nature of the employee benefits provided by the company, and (v) the impact on the business environment in general following from the impact of HIV/AIDS on other companies and on government (Loewenson \& Whiteside, 1997: 25). Case studies conducted in South Africa and other African countries present some information on the nature of this impact. So, for example, the cost of HIV/AIDS per employee has been estimated at between US\$49 and US\$300 (Whiteside et al., 1999; 5). In a sugar mill in KwazuluNatal the total annual cost per worker was estimated at R8464 (Morris et al., 2000: 940). HIV/AIDS-related costs to business have been estimated as ranging between 0.8 and 8.6 per cent of the total wage bill (Aventin \& Huard, 2000: 172; Thea et al., 2000) and between 3.4 and 20 per cent of profits (Guinness \& Alban, 2000: 9). Metropolitan has put the increase in the wage bill as a result of HIV/AIDS at respectively 25 and 45 per cent by 2005 and 2010 (ING Barings, 2000: 12). According to the results of these studies, the major components of HIV/AIDS-related costs are absenteeism, employee benefits and health care. The mining, transport and storage, construction, and catering and accommodation sectors are amongst those most vulnerable to the impact of HIV/AIDS (ING Barings, 2000: 29). Although a number of large companies in South Africa have conducted studies on the impact of HIV/AIDS on their costs, little if any research has been conducted that will present a picture of how business in general will be affected. Hence the cost to business of future AIDS deaths and the value of benefits from intervening so as to extend the working lives of HIV-positive employees and prevent the spread of HIV/AIDS remain largely unknown. 


\section{AIMS AND OBJECTIVES}

In a recent article, Rosen et al. (2000) present some calculations of the future benefits to firms of getting involved in combating HIV/AIDS. The assumptions, though, on which their calculations are based are derived from studies conducted in other countries (i.e. Malawi and Botswana) or from case studies of select South African companies. These assumptions are not necessarily equally applicable to businesses operating in the Free State province. In order to put a more accurate value to the benefits for business of extending the working lives of HIV-positive employees and of combating the spread of HIV/AIDS, certain information related to the economic impact of HIV/AIDS were collected from businesses in Bloemfontein and Welkom. Based on the assumptions derived from this data and results presented in other studies, the future costs of AIDS to business are estimated. These costs are then compared with the cost of now intervening in the workplace so as to extend the working lives of HIV-positive employees and combat the spread of the epidemic. Michael (2000: 8 ) emphasizes the importance of such case studies in expanding the limited information on the costs of HIV/AIDS to business in South Africa that is in the public domain.

In certain case studies of individual companies employees are actually subjected to HIV-testing, which is conducted in an anonymous and random manner. The resulting estimates of HIV prevalence in the workplace are used to project future changes in the workforce, which is required for costing the impact of HIV/AIDS in the particular setting (Morris et al., 2000). This approach was not followed in this study. The researchers simply did not have the resources or time to obtain approval from such a large number of businesses to conduct HIV/AIDS testing and the procedure prescribed by law, e.g. the provision of pre- and post-counselling. The project was aimed at doing a quick study that will inform the members of the Chambers of Business in Bloemfontein and Welkom about the likely impact of HIV/AIDS. Hence, the focus is on integrating primary and secondary data from a variety of sources, e.g. information obtained from companies themselves and published findings available from the literature, to estimate the cost of HIV/AIDS for businesses in the two selected sites. Hopefully, this work will encourage individual companies to avail researchers the opportunity to conduct more in-depth studies in specific settings, which will contribute much to the rather sparse literature on the impact of HIV/AIDS on the private sector that is in the public domain. Such research is also crucial for improving the assumptions made in studies of this nature. 
The need for adequate data was balanced with the need for an acceptable response rate in designing the self-administered questionnaire used for the purposes of data collection amongst business organizations. The questionnaire, amongst other things, collected information on the type of industry, the number of employees, the composition of the workforce by age, gender, race and skill level, the average annual wage/salary bill, and average annual turnover. Data were also collected on the nature of pension and employee benefits accruing to employees that are medically retired or pass away whilst in the service of the employer, sick leave, funeral leave and expenses, in-house health care services, and recruitment and training of new employees. This represents the background financial and human resource data required to estimate the impact of HIV/AIDS on business. Information was also collected on the extent to which businesses have implemented or intend implementing HIV/AIDS programs in the workplace. Businesses were also asked to indicate the amounts they are willing to pay to avert AIDS deaths amongst certain categories of employees.

Questionnaires were distributed among more than 200 randomly selected businesses in Bloemfontein and Welkom between December 2000 and January 2001. By March 2001 completed questionnaires were received from a total of twenty firms, ten each in Bloemfontein and Welkom. Admittedly, this response rate is relatively poor. However, self-administered questionnaires in general have a very low response rate. In addition, the lack of resources to do regular follow-ups so as to improve the response rate also contributes to the problem. Yet, the information still provides some indication of the manner in which businesses in these two towns are dealing with the AIDS crisis. In terms of the standard international industrial classification (SIC), nine of the twenty firms were from wholesale and retail trade, maintenance and repair services. Two businesses each were from the construction and the real estate, renting and business activities industries respectively. The remaining seven businesses represent each of the following industries: (a) agriculture, hunting and forestry, (b) manufacturing, (c) hotels and restaurants, (d) financial intermediation, (e) education, (f) health and social work, and (g) other community, social and personal services. The twenty businesses in total employed 1600 employees. The average number of employees per business ranged from 2 to 1000 with an average of 80 . Three quarters of the businesses employed twenty or less workers. The average annual turnover of these businesses over the last five years amounted to R11.6 million, ranging from R70000 to R100 million. Given these particulars, these businesses can mainly be described as small to mediumsized enterprises. This lends a unique perspective to this particular case study. Companies involved in other case studies were mostly subsidiaries of large national or multinational business corporations. The ILO (2000: 30), furthermore, emphasizes the need to expand the available knowledge on the 
impact of HIV/AIDS on smaller enterprises, which employs the majority of workers.

The data collected from these businesses is combined with 1996 census data and estimates from other studies of the economic impact of HIV/AIDS on business to estimate the cost of AIDS to business. Due to constraints of space, combined results are here presented for Bloemfontein and Welkom rather than distinguishing between these two individual towns in the Free State province.

\section{COST OF AIDS TO BUSINESS}

In order to estimate the cost of AIDS to business one first requires an estimate of the number of AIDS deaths. ING Barings (2000: 8) reports estimates of the number of AIDS deaths per 100 workers, based on projections made with the aid of the ASSA600 model. A distinction is made between highly skilled, skilled, and semi- and unskilled workers ${ }^{2}$. The model makes certain restrictive assumptions about risk behavior and changes in behavior. The estimates of the number of AIDS deaths may look rather different when these assumptions are changed. However, this model remains the only readily available source of projections of the estimated number of future AIDS deaths. The number of AIDS deaths for 2001-2010 is estimated by multiplying the former ratio with the number of employed persons in Bloemfontein and Welkom aged 15-59. The 1996 census data is used for this purpose ${ }^{3}$. This represents the only data source that reports a relatively recent estimate of the number of employed persons in these two Free State towns. This calculation of the number of AIDS deaths is based on the explicit assumption that the workforce remains stable over the next ten years and that workers that do die as a result of AIDS are replaced with newly recruited employees.

The predicted number of AIDS deaths is reported in Table 1. Evident from Table 1 is that the largest share of deaths will occur amongst semi- and unskilled employees, given that the prevalence of HIV amongst these employees is assumed to be relatively high. However, no employees are exempt from the epidemic. Employees dying from AIDS also include a considerable number of highly skilled and skilled employees. 


\section{Table 1 Predicted number of AIDS deaths in Bloemfontein and} Welkom (2001-2010)

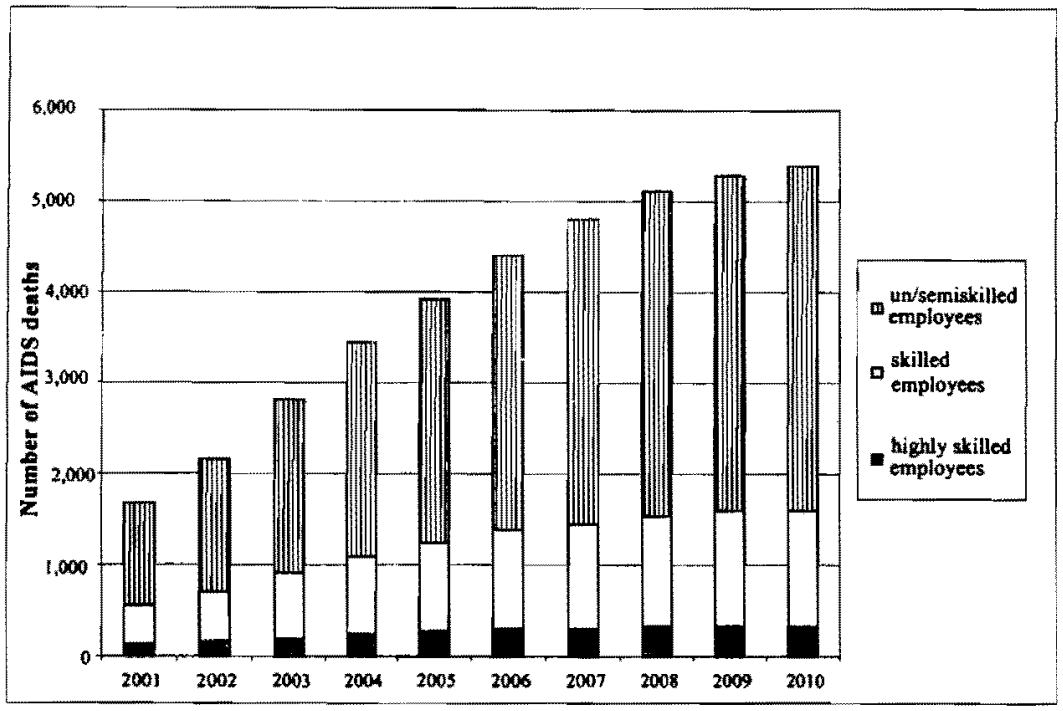

The specific costs resulting from these AIDS deaths need to be identified and quantified in a specific manner. Certain costs pertain to individual infected employees, e.g. absenteeism and employee benefits. Other costs resulting from the impact of HIV/AIDS concern all employees, e.g. rising medical aid premiums and funeral attendance. The cost to business of individual AIDS deaths is assumed to accrue in the last two years before the infected employee dies (Rosen et al, 2000: 302). Values for 2001 are inflated by five per cent per annum to determine the value of these AIDS-related costs in each of the subsequent years. An average annual inflation rate of five per cent is considered justified insofar as this represents the upper limit of the inflation targets recently announced by the South African Reserve Bank. The predicted inflation rate employed in the macroeconomic forecasts for the next three financial years also falls within this range (National Treasury, 2001: 38). The individual components of AIDS costs are treated in the following manner in calculating the cost of future AIDS deaths to business in Bloemfontein and Welkom. The calculations employed in estimating the number of AIDS deaths, each of the cost components, and the average cost of AIDS per employee and per AIDS death are described in an appendix to this paper. 


\subsection{Recruitment and training costs}

AIDS-related deaths of employees require that businesses replace these workers, which involves expenses regarding recruitment and training. Businesses that participated in the survey were asked to indicate the number of new employees recruited over the past five years and the average annual amount spent on recruiting and training these new employees. The twenty firms that returned completed questionnaires on average spent R6804 per new recruit. This amount is substantially lower than the estimate of R8405 employed by Rosen et al. (2000: 302) and which was obtained from a study of five companies conducted in Botswana. Given that these relatively small or medium-sized businesses in Bloemfontein and Welkom utilize less expensive recruitment channels and agents than large business corporations, this assumption may be justified. The AIDS-related cost pertaining to recnitment and training is calculated by multiplying the number of AIDS deaths for each year by R6804 after adjusting for the effect of inflation.

\subsection{Cost of employee benefits}

Businesses also need to pay employee benefits to workers that die whilst in their service or who are retired on medical grounds as a result of AIDS. The majority of the businesses consulted during the survey indicated that they do provide pension benefits to employees. The reported value of these benefits range from one to four times annual salary. However, seventeen of the twenty firms indicated that they do not offer any such benefits when employees opt for medical retirement. In other studies an assumption is sometimes made about the proportion of HIV-positive employees that die whilst in service and that are boarded medically (Thea et al., 2000). For simplicity, it is assumed that infected employees do not accept medical retirement and that these benefits are paid to their dependents as a pension. The cost of these employee benefits is estimated at three times the average annual salary of the deceased worker. Rosen et al. (2000: 302) employed a similar assumption. The total value of employee benefits related to AIDS deaths is calculated by multiplying by three the average annual salary of highly skilled, skilled, and semi- and unskilled workers, as calculated from the data collected during the business survey. To obtain the total cost, this figure is multiplied with the annual predicted number of AIDS deaths in each of the three skill categories (Table 1).

\subsection{Sick leave}

A third major cost of AIDS results from the increased absenteeism of infected workers due to illness and due to funeral attendance. The majority of the firms consulted in the business survey indicated that they offer employees the ten 
days of paid sick leave per annum stipulated in the Act on Basic Conditions of Employment. Businesses were not asked about actual trends in absenteeism, because it is impossible to distinguish AIDS-related absenteeism from nonAIDS-related absenteeism without knowing the identity of infected workers. Moreover, infected employees are likely to in the last two years of their illness be absent for considerably longer than ten days. A study by ING Barings (1999) has estimated that total absenteeism could amount to as much as 250 productive days per infected employee over the course of the illness. Given that the data collected from the business survey does not allow the number of days infected employs will be absent from work to be estimated directly, the relatively conservative assumption that Rosen et al. (2000: 302) employ for this purpose is used here. They assume that absenteeism resulting from AIDS amounts to 55.5 days sick leave per infected employee; spread equally over the two years before the death of the infected employee. The cost of absenteeism is calculated by multiplying the average number of days of sick leave by double the daily salary, which is calculated from average salary levels. This is considered a conservative but acceptable approach to putting a value to the direct and indirect cost of absenteeism. Businesses not only have to pay workers a salary while they are absent from work, but may also have to hire replacements and/or take into account that the absence of these workers results in productivity losses.

\subsection{Funeral attendance}

The AIDS epidemic will also have an impact on the leave that employees take to attend funerals. One would expect the number of person days lost due to funeral attendance to increase as the AIDS epidemic intensifies, i.e. as an increasing number of co-workers and family members of employees die as a result of AIDS. This particular cost applies to all employees and not only ones infected with HIV, thus emphasizing the point that all people are ultimately affected by the AIDS epidemic. As in the case of sick leave, the business survey only collected information on the number of days of funeral leave offered to employees. Again the majority of businesses indicated that they offer the three days per annum stipulated by the Act on Basic Conditions of Employment. Furthermore, it is not possible to distinguish between funeral attendance related to AIDS deaths and other causes of death. Hence, this particular cost component is quantified only in relation to the number of AIDS deaths amongst employees. It is assumed that for each worker that dies of AIDS, one highly skilled employee, one skilled employee, and one semi- or unskilled employee will each take two days funeral leave. As in the case of absenteeism, the cost of funeral leave is calculated by multiplying the two days of funeral leave by double the daily salary of the employees that are assumed to take such leave. This number is multiplied by the number of AIDS deaths to 
obtain the total cost to business of funeral attendance. Although this assumption is very conservative, it should present an acceptable proxy of the additional working days lost as a result of funeral attendance resulting from AIDS deaths.

\subsection{Funeral expenses}

In the case of funeral expenses, only one of the twenty businesses consulted during the survey indicated that they contribute to the burial costs of employees that die whilst in their service. For this sample of businesses, therefore, this particular cost of AIDS remains the responsibility of the kin of the deceased rather than their employer. Consequently, this cost component is excluded from this analysis.

\subsection{Cost of health care services}

Certain businesses provide their employees with in-house medical or health care services. In the face of the AIDS epidemic these direct medical costs to business of AIDS deaths should increase substantially. However, the majority of the businesses consulted during the survey do not provide such services. Where the particular question was answered in the affirmative, it simply related to emergency medical care provided in the case of occupational injuries. Consequently, this particular component of AIDS costs is excluded from this analysis. None of the twenty businesses indicated that they are currently spending money on HIV/AIDS programs, which also removes this element of the direct cost of AIDS from the analysis.

\subsection{Medical aid premiums}

Lastly, there is the fact that medical aid premiums will increase as insurers come under increasing pressure and pay-outs to HIV-positive patients increase. As in the case of funeral leave, this particular cost applies to all employees with access to such benefits and not only to employees dying from AIDS. A quarter of the businesses participating in the survey indicated that they do offer their employees medical aid benefits. The contribution of these businesses to their employees' medical aid funds ranged between five and ten per cent of the person's salary. The contribution in most cases was shared equally between the employer and employee. On closer inspection of the data it was found that the majority of employees in the service of businesses offering these benefits are highly skilled employees. In turn businesses not offering these benefits mostly employ skilled, semi-skilled and unskilled workers. Hence AIDS costs related to increased medical aid premiums are only calculated for highly skilled employees. The average medical aid premium paid by the employer is 
calculated as 7.5 per cent of the average salary of highly skilled employees. This premium is escalated by 9.4 per cent per annum, which represent the average increase in medical aid premiums reported by Thea et al. (2000). The AIDS-related increase in premiums was then determined by multiplying the number of highly skilled employees by the annual difference between the normal and escalated medical aid contribution per employee.

\subsection{Total cost of AIDS to business}

In order to estimate the total cost to business of AIDS the value of each of the above cost components was first estimated. The total annual cost was then obtained by adding up each of the five cost components. A distinction is made between AIDS costs pertaining to highly skilled, skilled, and semi- and unskilled employees. These values, like those presented elsewhere in these pages, are present values. Present values are calculated by discounting the future cost of AIDS at ten percent per annum, which approximates the difference between the interest rate and inflation rate (i.e. the so-called real interest rate). This adjustment is necessary so that the cost of current interventions can be compared to the savings to be gained from extending the working lives of HIV-positive employees or of preventing one infection and therefore one future AIDS death.

Table 2 Total annual cost of AIDS to business in Bloemfontein and Welkom (2001-2010)

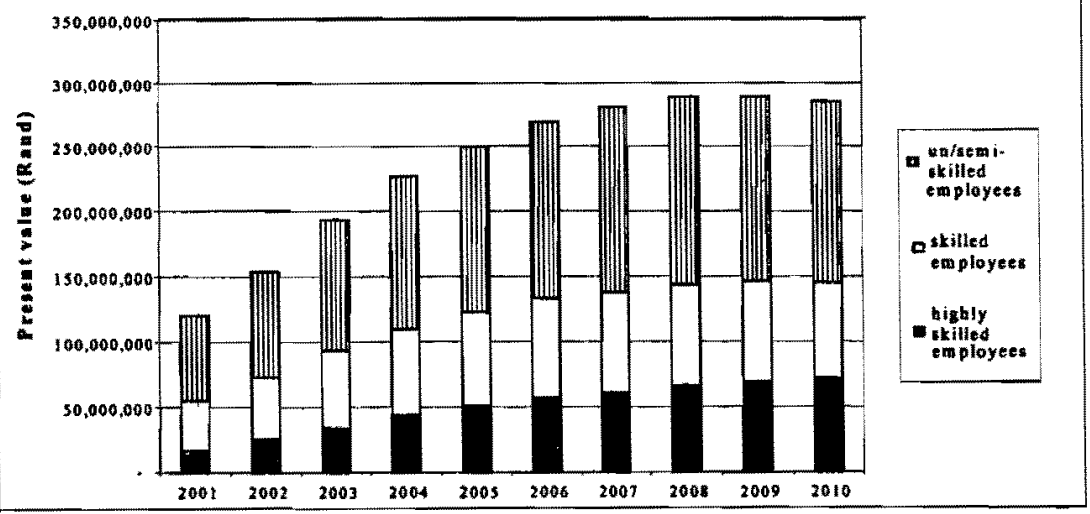

The total cost of AIDS to business in Bloemfontein and Welkom is substantial (Table 2). The average annual present value of the cost amounts to nearly R236 
million, while the total present value of these annual costs adds up to close to R2.4 billion over the period of ten years. Annual costs continue to increase and peak in 2009 when the AIDS epidemic is assumed to reach its turning point. Table 3 reports on the distribution of the total annual cost of AIDS by level of skill.

Table 3 Distribution of total annual costs of AIDS to business in Bloemfontein and Welkom by level of skill (2001-2010)

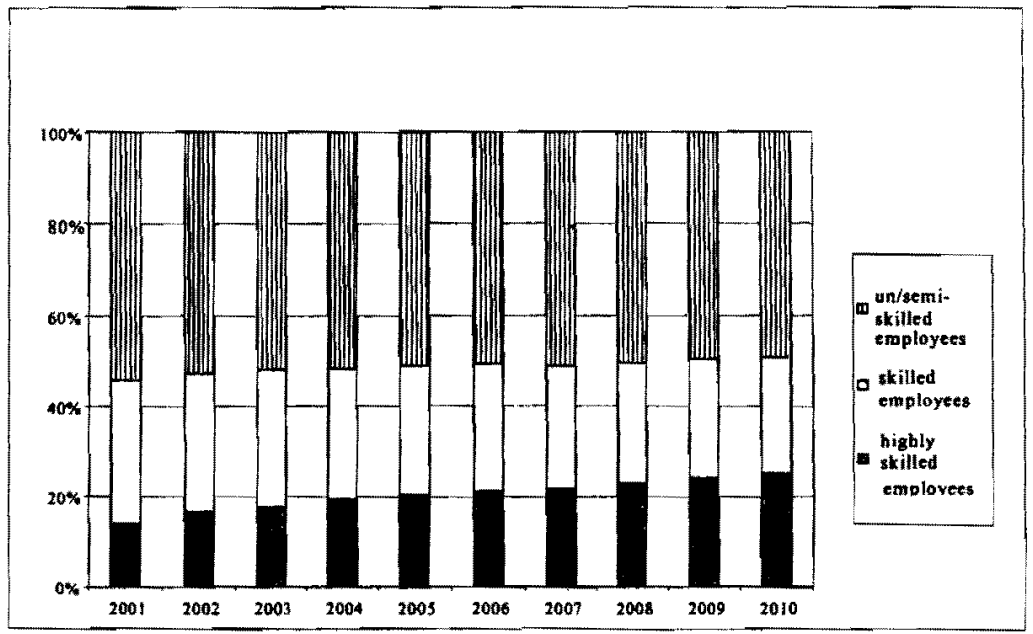

Because the number of AIDS deaths amongst semi- and unskilled workers exceeds that amongst highly skilled and skilled workers (Table 1), the largest share of the aggregate cost of AIDS can be attributed to deaths amongst semiand unskilled employees. On average just more than half of the total cost of AIDS accrues to semi- and unskilled workers over the period of ten years. Skilled and highly skilled workers on average share respectively twenty-nine and twenty per cent of the total cost of AIDS over the period. Cohen (2000) reports a similar trend in the distribution of the cost of AIDS between employees of different levels of skill.

\subsection{Limitations of the study}

The above estimates and those presented elsewhere in these pages represent a relatively conservative estimate of the cost to business of HIV/AIDS. In fact, the estimates for a variety of reasons most likely present an underestimation of these costs; for example, the labor force was assumed to remain constant over 
the next ten years. It was also assumed that employees that die as a result of AIDS are replaced. Different assumptions about this, e.g. that the workforce increases as the economy grows or that not all infected employees are replaced once they die, would have seen costs either increase or decrease, depending on the specific nature of these assumptions. This study only quantifies a relatively small number of the cost components of AIDS. The analysis does not attempt to put a value to the so-called systemic costs of AIDS, e.g. the impact of a loss of workplace cohesion and workforce experience or the external impact resulting from changes in demand and the introduction of legislation governing HIV/AIDS in the workplace. Nor are indirect costs such as those resulting from reduced productivity and an increased management burden quantified here (Whiteside \& Sunter, 2000: 110-12). These costs can only be estimated following an in-depth study of specific firms, which falls outside the scope of the business survey conducted for the purposes of this analysis. Furthermore, a proportion of skilled employees also has access to medical aid benefits, which will further increase the AIDS-related cost to business of escalating medical aid premiums. The assumption made about time lost to funeral attendance is relatively conservative and more man-days are likely to be lost through increases in funeral attendance. The major costs following from an AIDS is assumed to accrue in the last two years before the infected employee's death. Yet, earlier episodes of illness will also lead to increased absenteeism, with a corresponding increase in the estimated costs of the impact of HIV/AIDS. Also, national estimates of the predicted number of AIDS deaths were used to calculate these cost estimates for Bloemfontein and Welkom. In terms of recent sero-prevalence data, the Free State province faces a more severe and faster growing AIDS epidemic than many of the other provinces in South Africa (Cohen, 2000). Hence the number of AIDS deaths may be underestimated, which in turn implies that the total cost of AIDS to businesses in Bloemfontein and Welkom is also underestimated. In terms of the comparison of these costs to the cost of current interventions to determine the benefit to business of intervening now, the estimated return on current interventions will also be underestimated. This means that the message to business that current interventions are worthwhile becomes of even greater importance. This, in combination with the fact that this study relies on information obtained from a relatively small sample of businesses (20), means that the extent to which the findings can be generalized to all businesses in these two towns and in the Free State province as such may be problematic. 


\section{Figure 1 Composition of cost of AIDS to business in Bloemfontein and} Welkom (2001-2010)

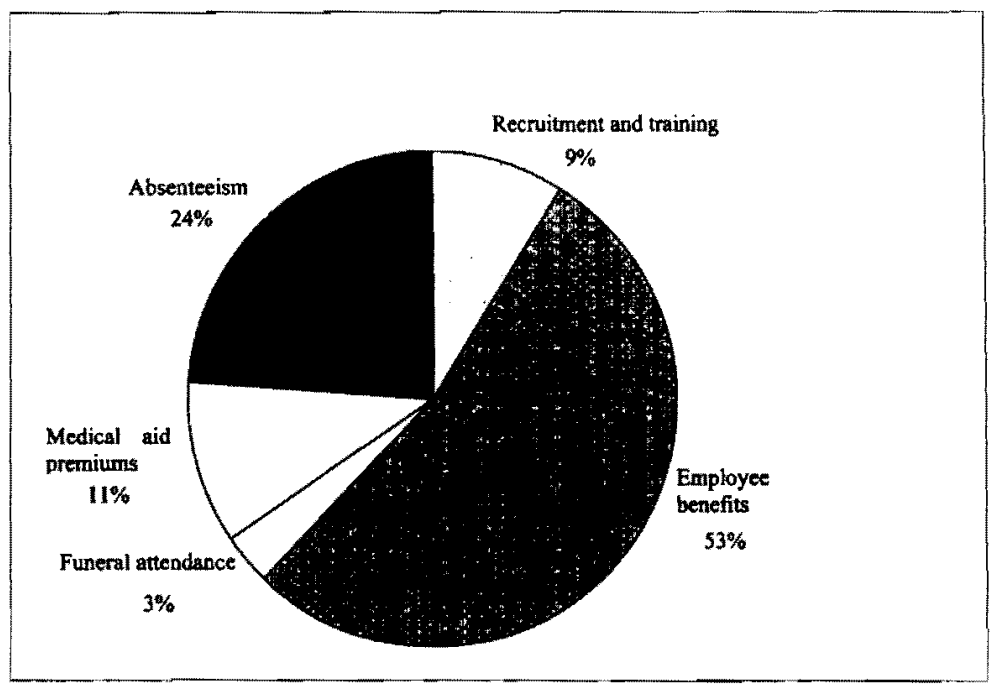

\subsection{Composition of cost of AIDS}

The composition of the total cost of AIDS is also of interest in studies of this nature. Figure 1 represents the percentage share of each of the five cost components in the total cost of AIDS. These results are not directly comparable to findings from other studies, which may employ different assumptions and include different cost components in estimating these costs. However, the results broadly correspond to findings presented in other studies. Employee benefits and absenteeism here represent the major components of AIDS costs, respectively contributing fifty-three and twenty-four percent to total costs. In other studies these two cost components consistently feature amongst the largest cost components. So, for example, Thea et al. (2000) report pensions to make up between forty and seventy per cent of total cost, while Aventin and Huard (2000: 167) put this at twenty-four per cent. Aventin and Huard (2000: 167) estimate that absenteeism contributes between eighteen and thirty-one per cent to total AIDS costs. Whiteside and Sunter (2000: 101) report an estimate of fifty-two per cent for absenteeism from a study conducted across a number of countries. 


\subsection{Average cost per employee and per AIDS death}

Estimates of AIDS costs can also be presented as the average AIDS cost per employee (Table 4) and the average cost per AIDS death (Table 5). The respective estimates are calculated by dividing the total cost of AIDS by the total number of AIDS deaths and the total number of employees. Averages are reported for all employees as well as for each of the three different categories of employees, i.e. highly skilled, skilled, and semi- and unskilled workers. These estimates present a better indication to business of the relative cost of AIDS than estimates of aggregate costs. It also presents important proxies to be employed in determining the value of implementing HIV/AIDS interventions in the workplace.

Table 4 Average cost of AIDS per employee (2001-2010)

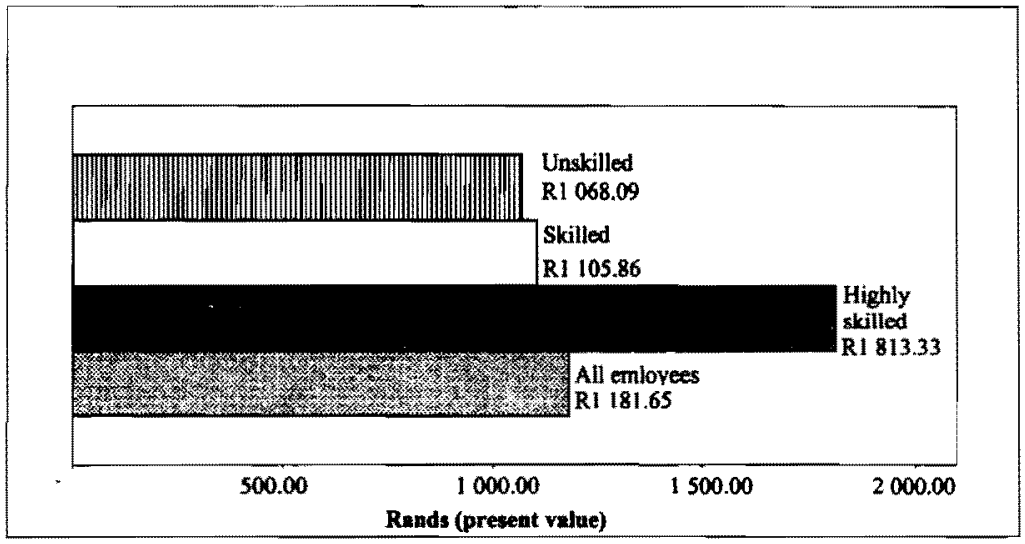

As expected, the average cost per employee increases as the level of skill increases. There are two reasons for this. First, cost depends on salary, which means that costs increase as the average salary increases. Second, the cost of increased medical aid premiums was assumed to accrue only to highly skilled employees. As in the case of the composition of AIDS costs, these estimates cannot be directly compared to results reported in other studies. Broadly speaking, though, the results again confer with other findings. Whiteside $e t$ al. (1999: 5), for example, report a range of estimates of the annual cost of AIDS per employee of between US\$49 and US\$300. The above estimates, when translated into US dollars using the current exchange rate (R7.84 per US\$1), equate to between US\$231 (highly skilled employees) and US\$136 (semi- and unskilled employees). These values fall well within the range of estimates reported by Whiteside et al. (1999). 
Table 5 Average cost per AIDS death (2001-2010)

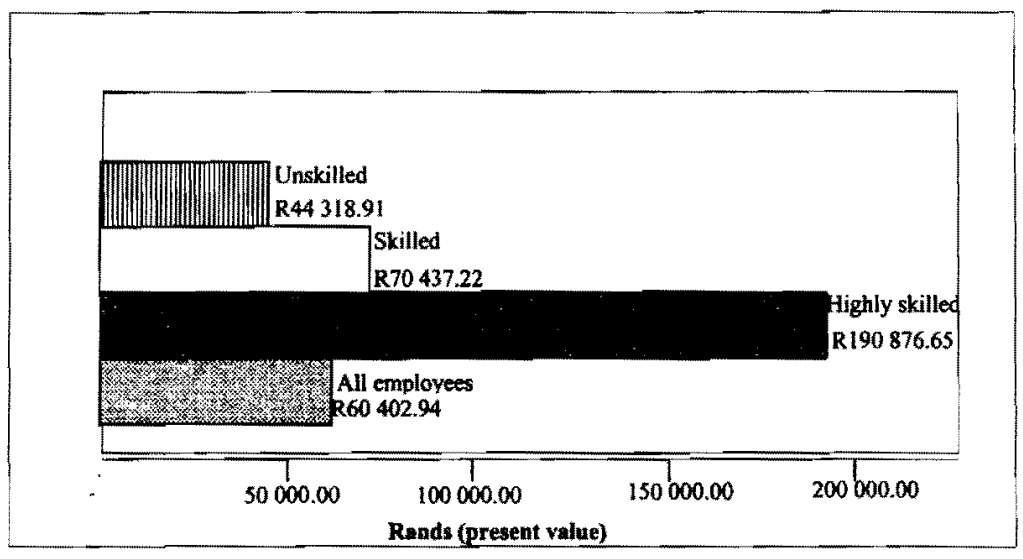

As in the case of the AIDS cost per employee, the average cost per AIDS death increases as the level of skills increases. Although a different methodology is employed here to estimate the cost of AIDS, the estimates correspond closely to those estimated by Rosen et al. (2000) Rosen et al. (2000: 303) estimated the cost per AIDS death respectively as R181222 (highly skilled employee), R92767 (skilled employee), and R48540 (semi- or unskilled employee). The average cost per AIDS death reported in Table 5 respectively represents 2.5 times (highly skilled), 1.27 times (skilled), and 1.35 times (semi- and unskilled) the average annual salary of these classes of employees. These estimates correspond relatively well with some of the findings reported elsewhere, but are also substantially lower than other estimates. Michael (2000: 8), for example, puts the cost per AIDS death at between three and four times the annual salary of the infected. employee. Cohen (2000) though, reports estimates of respectively $6.8,5.1$ and 5.2 times the annual salary of highly skilled, skilled and unskilled employees. As argued elsewhere, these differences can be attributed to differences in the particular methodology employed in estimating the cost of AIDS.

\section{BENEFITS TO BUSINESS OF CURRENT INTERVENTIONS}

The most important parameter of the cost of AIDS with which to compare the cost of current interventions is the present value of the cost per AIDS death. These estimates were reported in Table 5 and can be compared to the cost of current interventions in one of two ways. 
First, there is the option of extending the working life of infected employees. This will allow businesses to keep infected employees in productive service for longer, implying less interruption in production and reduced labor turnover. If business can manage to extend the working life of an HIV-positive employee by one year or more it also means that the current value of the future cost per AIDS death will be discounted over a longer period of time. This will reduce the current value of the cost per AIDS death. Assume, for example, that the working life of all HIV-positive employees can be extended by one year. This means that the cost per AIDS death will be discounted over a period of eleven rather than ten years. The difference between the average cost per AIDS death discounted over eleven as opposed to ten years amounts to R5491.18. Table 6 reports the average savings per infected employee for highly skilled, skilled, and semi- and unskilled employees. Savings are also calculated across all employees. Savings as percentage of the baseline cost per AIDS death (Table 5) increase from nine to thirty-eight per cent as the working life of the infected employee is extended with one to five years.

Table 6 Average savings per infected employee of extending the working life of HIV-positive employees in Bloemfontein and Welkom (2001-2010)

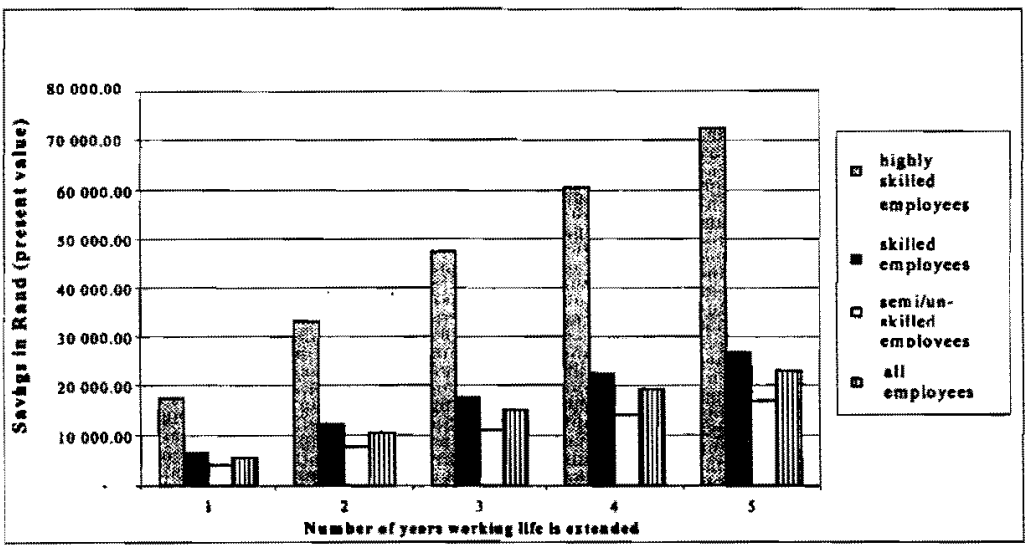


According to Rosen et al. (2000: 303) there are relatively inexpensive ways to extend the working lives of HIV-positive employees. They elaborate on three specific examples. A study in Spain found that a single twelve-month course of tuberculosis prophylaxis (isionazid), which costs approximately R40.00 per annum, on average increased the median survival time of HIV-positive adults by three years. In a study conducted in the Ivory Coast it was found that a daily dose of prophylactic cotrimoxazole administered to HIV-positive adults from discovery of infection until death reduced the rate of severe events leading to hospitalization or death with forty-three per cent. This drug costs approximately R90.00 per annum, while the discounted cost of ten years of therapy amounts to nearly R500 per patient. Counseling and other psychosocial interventions can be equally useful in extending the working life of infected employees. In the United States, for example, a study found that such interventions reduced the probability of developing AIDS at 5.5 years after infection by two to three times among adult men (Rosen et al., 2000: 303). Although no details are available about the likely cost of such interventions, these costs may be relatively modest compared to the substantial savings per AIDS death reported in Table 6 . No information is available on the cost of HIV/AIDS interventions in South Africa and more work is required in this regard. The cost of the first two interventions described here (i.e. isionazid and cotrimoxazole) is relatively low compared to the benefit to be gained from extending the working life of infected employees. The combined cost of these two drugs make up less than ten per cent of the average savings per AIDS death of extending the working life of HIV-positive employees by just one year. This represents a tenfold retum on such investment. These costs are also much lower than the amounts that surveyed businesses indicated they are willing to pay to avert a single AIDS death or that they are willing to allocate to such programs in future budgets. Thus, relatively inexpensive interventions, if launched now, can yield substantial returns and save business considerable amounts of money. Furthermore, particularly in terms of counseling and psychosocial interventions, interventions need not require additional resources to be channeled toward such initiatives. It may, for example, be possible to assign such responsibilities to the human resources and/or occupational health functions of management without incurring additional costs. The above results gain even greater significance when considering that none of the businesses consulted during the survey currently have any HIV/AIDS program running in the workplace.

Alternatively, the benefit to business of managing to avert one future AIDS death through current interventions would equal the cost per AIDS death minus the cost of the particular intervention. This issue can be best analyzed with reference to the information obtained from a business survey. Businesses were asked what they are willing to allocate toward implementing HIV/AIDS programs in the workplace and what they are willing to pay to avert a single 
AIDS death amongst certain groups of employees. Only five of the twenty firms indicated that they are willing to allocate money toward HIV/AIDS programs in future budgets. These moneys amount to an average of R120 per employee, ranging from $\mathrm{R} 2.13$ to $\mathrm{R} 1333$ per employee. In the case of the question on willingness-to-pay, seven of the twenty businesses indicated that they are willing to spend some money to avert an AIDS death. These amounts range from $\mathrm{R} 100$ to $\mathrm{R} 50000$, while the average amount the said firms were willing to pay to avert one AIDS death amount to R6884. When taking the education or skill level of employees into account, the average amount ranges from R7412 (highly skilled employee) to R6294 (unskilled employees). These amounts are relatively modest compared to the benefits of managing to avert one AIDS death. Assume, for example, that a business spends somewhere between R6884 and R9600 this year to implement an HIV/AIDS program in the workplace. The former estimate represents the average willingness-to-pay to avert a single AIDS death, while the latter represents an annual HIV/AIDS budget of R120 per employee, given an average labor force of eighty. If the said program is successful in preventing just one employee from becoming infected and dying ten years from now, the investment will yield a 4.5 to 6.5 fold retum relative to the average cost per AIDS death of R52 883 for 2010 . Therefore, relatively modest investments in current interventions can yield considerable returns, given of course that such programs are effective. Employees attach considerable weight to information received in the workplace, which highlights the importance of the workplace as a site for information and education programs (Famham, 1991: 663).

\section{CONCLUSIONS AND POLICY IMPLICATIONS}

Over the next ten years, as the AIDS epidemic takes its toll on the economically active population, employers will incur considerable costs. However, relatively inexpensive interventions, if launched now, can yield substantial returns and save business considerable amounts of money, given that such programs are implemented effectively and efficiently. Both interventions aimed at extending the working life of currently infected employees and interventions aimed at preventing future AIDS deaths are economically feasible. Worrying, though, is the fact that a large proportion of businesses consulted during the survey indicated that they are not willing to spend money on HIV/AIDS programs or pay to avert AIDS deaths. Given that the survey mostly included small and medium-sized firms, this may simply reflect the inability of firms with a relatively low turnover and a small budget to allocate money to HIV/AIDS programs at a time when the national economy is still reeling from the recent recession. Yet, there does appear to be a general apathy on the part of many managers. Two quotes from the survey strikingly illustrate this negative 
sentiment on the part of certain managers. One business indicated that there are 'so many other people to replace the dead (and that) only people with degrees might be a problem'. Another business volunteered that 'we use people from the middle and even upper class who know (hopefully) everything about AIDS. (We) do not see the necessity of such a program. Everyone has a television and reads newspapers where the matter is discussed on a daily basis. I am not aware of any problem amongst my staff, and do not see why I must spend money on something which the firm will not benefit from'. This problem appears to not be unique to Bloemfontein and Welkom or the Free State province for that matter. Farnham (1991: 663) reports that a study conducted in 1987 amongst 623 US companies found that seventy-one per cent of these companies at the time neither had, nor planned to implement an AIDS policy in the workplace. A study conducted amongst local employers in North Nottinghamshire found that only twenty per cent of the eighty-six respondents had a policy on HIV/AIDS, with local businesses particularly, that are not subsidiaries of national or regional corporations, failing to implement such policies (Whelan et al., 1994: 101). In the case of Asia, Kimball and Myo (1996: 1) emphasize the lack of access to information and education in the workplace and failure of efforts to gain cooperation of business and industry in the fight against HIV/AIDS.

Hence much needs to be done to change these attitudes of business, not only in South Africa but also elsewhere. Moreover, the current policy environment, seems supportive of this increased role of business in the fight against HIV/AIDS. For example, the Code of Good Conduct on Key Aspects of HIV/AIDS and Employment issued in December 2000 emphasizes the role of employers in 'developing strategies to assess and reduce the impact of the epidemic upon the workplace' and 'supporting those individuals who are infected or affected by HIV/AIDS so that they may continue to work productively for as long as possible' (Department of Labour, 2000: 5). To this end companies should, according to Smart (2000: 14) establish so-called Care Task Teams that will develop a care strategy that describes (i) who will have access to care, (ii) what the care will consist of, and (iii) who will cover that costs. Components of such care strategy may include establishing support groups and networks of people living with HIV, supporting home-based care initiatives, and providing health services (Smart, 2000: 14). In South Africa, as in other countries (ILO, 2000: 27), employers have also formed a business coalition on HIV/AIDS (SABCOAHA) in order to pool resources and improve their response to the crisis. The private sector, government and NGOs should also consider initiatives that can support smaller firms in offering their employees training and counseling on HIV/AIDS. An example is the development of care and prevention programs financed via mutual health funds established for small enterprises (ILO, 2000: 30). Lastly, as Whiteside (2000: 5) emphasizes, the involvement of business in partnership initiatives in fighting 
HIV/AIDS and mitigating its impact should be based on a give-and-take relationship in which the benefits to business are clearly illustrated. It is hoped that this paper may contribute to this process of education and may encourage business involvement in an integrated, coordinated fight against HIV/AIDS by government, NGOs and communities.

\section{ENDNOTES}

1 An earlier version of this paper was presented at the International AIDS in Context Conference, 4-7 April 2001, University of the Witwatersrand, Johannesburg, South Africa.

2 The survey did not distinguish between highly skilled, skilled, and semiand unskilled employees, which is the classification of employees used here to estimate the cost of AIDS. Instead a distinction was drawn between employees with different levels of education. Consequently, employees with degrees were assigned to highly skilled category, ones with a certificate or diploma to the skilled category, and those with matric or less to the semi- and unskilled category.

3 The census results are reported in terms of the standard international classification of occupations. This classification does not allow for a distinction to be drawn between highly skilled, skilled, and semi- and unskilled employees, which is the classification of employees used here to estimate the cost of AIDS. Consequently, employed persons were assigned employed persons to the three skill categories for which AIDS death ratios are available using this classification. Highly skilled employees comprise of legislators, senior officials, managers and professionals. Skilled employees include technicians and associated professionals, clerks, skilled agricultural and fishery workers, and plant and machine operators and assemblers. Semi- and unskilled employees consist of service workers, shop and market sales workers, craft and related trades workers, and elementary occupations. 


\section{APPENDIX}

The estimates of the cost of AIDS to businesses in Bloemfontein and Welkom that are reported in these pages were calculated as follows:

(i) Number of AIDS deaths per skills category $=$ [(number of workers per skill category)/100] $\times$ estimated number of AIDS deaths per 100 workers per skills category.

(ii) Total number of AIDS deaths $=\Sigma$ number of AIDS deaths per skill category.

(iii) Cost of recruitment and training $=$ number of AIDS deaths $\times$ R6804.

(iv) Cost of sick leave $=$ number of AIDS deaths per skill category $\times(55.5$ days $\times 2 \times$ average daily salary per skill category).

(v) Cost of funeral leave $=$ number of AIDS deaths (ii) $\times[$ [ 2 days $\times 2 \times$ average daily salary of unskilled employee $)+(2$ days $\times 2 \times$ average daily salary of skilled employee $)+(2$ days $\times 2 \times$ average daily salary of highly skilled employee)].

(vi) Cost of increased medial aid premiums $=$ number of highly skilled employees $\times[(7.5$ per cent $\times$ average annual salary $) \times 9.4$ per cent $]$.

In calculating the results for each subsequent year (i.e. 2002 to 2010), the particular cost components (i.e. cost of recruiting one new employee, average daily salary and cost of medical aid premiums) were inflated at five percent per annum. The number of AIDS deaths in each of these years, was calculated based on the estimated number of deaths per 100 workers reported for 2001 to 2010 by ING Barings (2000: 8 ).

(vii) Average annual total cost of AIDS deaths $=\Sigma[($ iii $)+($ iv $)+(v)+($ vi) $) \times$ $(1 / 1.10)^{n}$ for each of the years 2001 to 2010 , where $n$ represents the number of years between the current year (2001) and each of the outer years (i.e. 2002 to 2010); calculated for all employees and per skills category.

(viii) Average cost per employee $=$ (vii)/number of employees; calculated for all employees and per skills category.

(ix) Average cost per AIDS death = (vii)/number of AIDS deaths; calculated for all employees and per skills category. 


\section{REFERENCES}

1 ABT ASSOCIATES (2000) The Impending Catastrophe: A Resource Book on the Emerging HIV/AIDS Epidemic in South Africa, Johannesburg: Henry J. Kaiser Family Foundation.

2 ARNDT, C. \& LEWIS, J.D. (2000) "Macro Implications of HIV/AIDS in South Africa: A Preliminary Assessment", South African Journal of Economics, 68(5): 856-87.

3 AVENTIN, L. \& HUARD, P. (2000) "Cost of AIDS to Three Manufacturing Firms in Côte d'Ivoire", Journal of African Economies, 9(2): 161-88.

4 BARNETT, T. \& WHITESIDE, A. (1998) Guidelines for Preparation and Execution of Studies of the Social and Economic Impact of HIV/AIDS. Geneva: UNAIDS.

5 BOLLINGER, L. \& STOVER, J. (1999) The Economic Impact of AIDS. Glastonbury, CT: Futures Group International.

6 COHEN, N.P. (2000) Economic Impact of HIV/AIDS on South Africa. Mimeo of presentation in Pretoria on May 25.

7 DEPARTMENT OF LABOUR (2000) "Code of Good Practice: Key Aspects of HIV/AIDS and Employment", Government Gazette, No. 21815: 3-17.

8 FARNHAM, P.G. (1991) "Knowledge, Attitudes, Beliefs, and Behaviors of the Business Community Relative to HIV/AIDS", Public Health Reports, 106(6): 663-66.

9 GUINNESS, L. \& ALBAN, A. (2000) Economic Impact of AIDS in Africa: A Review of the Literature, UNAIDS Background paper for African Development Forum 2000.

10 ING BARINGS (1999) Demagraphic Impact of HIV/AIDS on the South African Economy, Johannesburg: ING Barings.

11 ING BARINGS (2000) Economic Impact of AIDS in South Africa: A Dark Cloud on the Horizon, Johannesburg: ING Barings.

12 INTERNATIONAL LABOUR ORGANISATION (2000) HIV/AIDS: A Threat to Decent Work, Productivity and Development, Document for Discussion at the Special High-Level Meeting on HIV/AIDS and the World of Work, Geneva, 8 June.

13 KIMBALL, A.M. \& MYO, T. (1996) "Role for Business in HIV Prevention in Asia", Lancet, 347(9016): 1670-72.

14 LOEWENSON, R \& WHITESIDE, A. (1997) Social and Economic Issues of HIV/AIDS in Southern Africa, Harare : SafAIDS.

15 MICHAEL, K. (2000) "Unbelievable: AIDS Reporting in the Business Press", AIDS Analysis Africa, 10(4): 1-8. 
16 MORRIS, C.N., BURDGE, D.R., CHEEVERS, E.J. (2000) "Economic Impact of HIV Infection in a Cohort of Male Sugar Mill Workers in South Africa", South African Joumal of Economics 68(5): 933-46.

17 NATIONAL TREASURY (2001) Budget Review 2001, Pretoria: National Treasury.

18 ROSEN, S., SIMON, J.L., THEA, D.M. \& VINCENT, J.R. (2000) "Care and Treatment to Extend the Working Lives of HIV-Positive Employees: Calculating the Benefits to Business", South African Journal of Science, 96: 300-304.

19 SMART, R. (2000) "AIDS Care: Why and How should Industry Respond", Aids Analysis Africa, 10(5): 13-14.

20 THEA, D.M., ROSEN, S., VINCENT, J.R., SINGH, G. \& SIMON, J. (2000) Economic Impact of HIV/AIDS in Company A's Workforce, Mimeo.

21 WHELAN, S., MOUSLEY, A.A. \& WIGHT, J.P. (1994) "Survey of Employers' Policies on HIV and AIDS in North Nottinghamshire", Journal of Public Health Medicine, 16(1): 101-4.

22 WHITESIDE, A., (2000) "AIDS and the Private Sector", Aids Analysis Africa, 10(5): 1-6.

23 WHITESIDE, A., O'GRADY, M. \& ALBAN, A. (1999) How Will AIDS Impact on Your Business? 1998 Southem Africa Economic Summit, Update Session, 4 July.

24 WHITESIDE, A. \& SUNTER, C. (2000) AIDS: The Challenge for South Africa. Cape Town: Human \& Rousseau Tafelberg.

25 UNAIDS (2000) Report on the Global HIV/AIDS Epidemic, Available: http://www.unaids.org/ epidemic_update/report/index.html. 